Research Article

\title{
A cross-sectional study to assess burden of obstructive sleep apnoea among type 2 diabetic patients attending urban health centre in an urban slum of south India
}

\author{
Malatesh Undi*, Rachana R. Annadani, Bheemayya Badesaab
}

Department of Community Medicine, SS Institute of Medical Sciences \& Research Centre, Davangere, Karnataka, India

Received: 25 May 2016

Accepted: 13 June 2016

*Correspondence:

Dr. Malatesh Undi,

E-mail: malatesh.u@gmail.com

Copyright: () the author(s), publisher and licensee Medip Academy. This is an open-access article distributed under the terms of the Creative Commons Attribution Non-Commercial License, which permits unrestricted non-commercial use, distribution, and reproduction in any medium, provided the original work is properly cited.

\begin{abstract}
Background: Obstructive sleep apnoea (OSA) is repetitive episodes of partial (hypopnea) or complete (apnoea) upper airway obstruction during sleep, resulting in a reduction or stoppage of airflow, followed by awakenings from sleep. Numerous studies, have concretely established relationships between OSA, type 2 diabetes mellitus (T2DM), and obesity. As the obesity epidemic continues in India, the prevalence of OSA and T2DM will increase. Many patients with T2DM have OSA, but unfortunately majority of them don't know it and remain undiagnosed especially in urban slums. OSA must be detected and treated immediately instead of waiting for years to decide whether there is a problem or not. Hence, the present study was done. Objective of the study is to assess the magnitude of OSA among the type 2 diabetic patients attending urban health centre (UHC) of an urban slum.

Methods: This was a cross-sectional study done in an UHC of an urban slum in South India. The sample size was 71. After obtaining written informed consent, the data was collected from previously diagnosed T2DM patients attending UHC using a validated structured questionnaire (STOPBANG and ESS) by interview technique.

Results: $66.2 \%$ of subjects had high risk of OSA (35.2\% had intermediate risk and $31.0 \%$ had severe risk of OSA). $40.8 \%$ had excessive daytime sleepiness, EDS (22.5\% of participants had abnormal/severe EDS, $18.3 \%$ had moderate EDS).

Conclusions: Nearly two third of T2DM patients had high risk of OSA and half of them had EDS, which was not detected earlier during their routine visits to hospitals in urban slum.
\end{abstract}

Keywords: Diabetes, Obstructive sleep apnoea, Urban health centre, Sleepiness, Risk

\section{INTRODUCTION}

Sleep apnoea is characterized by the cessation of airflow during sleep. There are three main types: obstructive, central, and mixed, and Obstructive sleep apnoea (OSA) is the most common. OSA is repetitive episodes of partial (hypopnea) or complete (apnoea) upper airway obstruction during sleep, resulting in a reduction or stoppage of airflow, followed by awakenings from sleep. OSA is a chronic disorder that often requires lifelong care. The signs, symptoms and consequences of OSA are a direct result of derangements that occur due to repetitive collapse of upper airway. OSA is affecting between $2 \%$ and $4 \%$ of middle aged adult population $(3.6 \%$ in Indian adult population). It has been documented that OSA is a significant risk factor in the development of other clinical diseases including hypertension, cardiac arrhythmias, myocardial infarction, stroke, decreased cognitive abilities and excessive 
daytime somnolence and is associated with an increase in the frequency of motor vehicle accidents. ${ }^{1}$

Obesity is the strongest risk factor for OSA. Obesity increases the risk of OSA because excess weight deposits extra fat around the thorax, reducing chest compliance and functional capacity, while increasing oxygen demand. In addition, extra soft fat tissue builds up around the wall of the oesophagus, narrowing the airway. The increased fat composition also makes the airway more collapsible. $^{2,3}$

The past studies, found that among all of the sleep disorders, OSA has the strongest association with type 2 diabetes. It is possible that the relationship goes in both directions. OSA is associated with impaired fasting glucose, glucose intolerance, and type 2 diabetes, even after accounting age, sex, waist circumference, and obesity. Poor sleep quality and intermittent hypoxemia from OSA may serve as the catalyst for glucose dysregulation. Over a time these abnormalities may accelerate weight gain, which increases the severity of OSA. $^{4-7}$

The Sleep ahead study found that $86 \%$ of obese patients with type 2 diabetes had undiagnosed OSA; $33.4 \%$ had mild OSA, $30.5 \%$ had moderate, and $22 \%$ had severe. For type 2 diabetes patients who have untreated OSA, recent studies showed a clear relationship between the severity of OSA and glucose control. Compared to those without OSA, the adjusted mean $\mathrm{HbA1c}$ was $1.5 \%$ higher in those with mild OSA, $1.9 \%$ higher in those with moderate OSA, and $3.69 \%$ higher in severe OSA patients. Studies also suggest that many patients with type 2 diabetes have undiagnosed OSA and that, if untreated, OSA has adverse effects on glycaemic control. Numerous studies, both large population-based and clinical, have concretely established relationships between obstructive sleep apnoea, type 2 diabetes, and obesity. $^{8-11}$

As the obesity epidemic continues, the prevalence of OSA and type 2 diabetes will increase. Many patients with type 2 diabetes have OSA, but unfortunately majority of them are unaware of it and remain undiagnosed. $^{12}$ Given the adverse consequences of untreated OSA (hypertension, stroke, motor vehicle accidents, poor glycaemic control), OSA must be detected and treated immediately instead of waiting for years to decide whether there is a problem or not. Also, extensive review of literature showed that there was seldom any attempt to screen type 2 diabetics for OSA and excessive day time sleepiness (EDS) in health centres of urban slums in south India. This study was therefore designed to screen for the risk of OSA and daytime sleepiness in outpatients attending an urban health centre (UHC) of slum in central part of Karnataka, south India. This study improves our appreciation of the burden of OSA in urban slum diabetic patients and provides data for comparison with other populations. Hence, the present study was done with primary objective to assess the magnitude of Obstructive Sleep Apnoea (OSA) among the type 2 diabetic (T2DM) patients attending UHC in an urban slum. The secondary objective was to assess the magnitude of excessive day time sleepiness (EDS) among T2DM patients attending UHC in an urban slum.

\section{METHODS}

This was a cross-sectional study carried out in an urban health centre (UHC) in an urban slum of a district in central part of Karnataka, India. The study was approved by Institutional Ethics Review Board. Participants included all known Type 2 diabetic patients aged $>18$ years attending urban health centre (UHC) in an urban slum. Participants who were severely ill or having poor comprehension were excluded from the study. The sample size was calculated assuming $86 \%$ prevalence of OSA among type 2 diabetics. ${ }^{3}$ Taking $10 \%$ relative precision and confidence interval of $95 \%$ the sample size calculated to be 63 . Adding $10 \%$ as non-response error, final sample size calculated was 71 . The subjects were selected consecutively as per the outpatient attendance at urban health centre.

\section{Study tool}

The data was collected from study participants using a structured questionnaire (STOP BANG questionnaire and Epworth Sleepiness Scale) using interview technique and measurements as appropriate. STOPBANG questionnaire consists of information related to snoring, tiredness during daytime, observed apnoea, high blood pressure, BMI $>30 \mathrm{~kg} / \mathrm{m}^{2}$, Age > 50 years, neck circumference > $40 \mathrm{~cm}$, male gender. STOP BANG questionnaire is a validated concise and easy to use screening tool which will help to identify those with OSA. Total scores are interpreted as: High risk of OSA: Yes 5-8, Intermediate risk of OSA: Yes 3-4, Low risk of OSA: Yes 0-2 Or High risk of OSA: answering yes to three or more items and Low risk of OSA: answering yes to less than three items. The more features a patient has, the greatest the pre-test probability they have OSA, with sensitivities of $83.6 \%$, $92.9 \%$ and $100 \%$ for mild, moderate and severe sleep apnoea respectively. ${ }^{13,14}$

Epworth sleepiness scale (ESS) (0-24) was used to assess excess daytime sleepiness (EDS). The Scale had 8 questions each with score 0 to $3 ; 0=$ would never doze 1 $=$ slight chance of dozing $2=$ moderate chance $3=$ high chance. The total score was interpreted as: abnormal sleepiness 10-24, Moderate sleepiness 7-9, Normal sleep 0-6. The ESS assumes that subjects can remember whether or not and under what circumstances they have dozed off during the day as a part of their "usual way of life in recent times". Most patients can give meaningful reports about their aspect of behavior. ${ }^{15}$ 


\section{Procedure}

All type 2 diabetic patients attending the UHC were briefed on the purpose of the study and assured privacy and confidentiality of the information provided by them. Their written informed consent was also obtained at that time. After this, the data was collected using structured questionnaire and measurements as appropriate. The subjects were also informed of the result of their screening test for OSA, if found to be having OSA were referred to sleep clinic/tertiary centre for further evaluation and treatment as appropriate.

\section{Statistical analysis}

Data collected was verified, coded and entered into Microsoft Excel 2010 and analyzed using using EpiInfo version 7.1.5.0 (CDC, Atlanta) and results obtained were described in proportions/ percentages, mean and standard deviation. Chi square test \& Fisher Exact Test was used to test the association between categorical variables with level of significance, $\mathrm{p}<0.05$.

\section{RESULTS}

A total of 71 participants were included in the study. 44 $(62 \%)$ of them were males and $27(38 \%)$ were females. Mean age of subjects was 56.39 years \pm 9.42 (standard deviation). Mean BMI was $25.95 \mathrm{~kg} / \mathrm{m}^{2} \pm 4.56$ (standard deviation). Mean Neck circumference of study participants was $38.83 \mathrm{~cm} \pm 4.71$ (standard deviation) (Table 1).
$66.2 \%$ of participants had high risk of OSA $(35.2 \%$ had intermediate risk and $31.0 \%$ had severe risk of OSA) (Table 2).

OSA was found to have statistically significant association with age $>50$ years $(\mathrm{p}=0.00002)$, neck circumference $>40 \mathrm{~cm}(\mathrm{p}=0.0026)$, male sex $(\mathrm{p}=0.045)$. $87.5 \%$ of obese participants had high risk of OSA as compared to $63.5 \%$ among those who had $\mathrm{BMI}<30 \mathrm{~kg} / \mathrm{m} 2$, however the association was not found to be statistically significant (Table 3 ).

Table 1: Distribution of study participants based on their age and anthropometric measurements $(n=71)$.

\begin{tabular}{|lll|}
\hline Parameter & Mean & $\begin{array}{l}\text { Standard } \\
\text { deviation }\end{array}$ \\
\hline Height (in $\mathrm{cm})$ & 162.28 & 8.38 \\
\hline Weight $($ in $\mathrm{kg})$ & 68.75 & 13.24 \\
\hline Body mass index (in $\left.\mathrm{kg} / \mathrm{m}^{2}\right)$ & 25.95 & 4.56 \\
\hline Neck circumference $($ in $\mathrm{cm})$ & 38.83 & 4.71 \\
\hline
\end{tabular}

Table 2: Distribution of study participants based on their risk of obstructive sleep apnoea (OSA) assessed by using stopbang questionnaire $(\mathrm{N}=71)$.

\begin{tabular}{|lllll|}
\hline Sex & $\begin{array}{l}\text { Low risk } \\
\text { of OSA }\end{array}$ & $\begin{array}{l}\text { Intermediate } \\
\text { risk of } \\
\text { OSA }\end{array}$ & $\begin{array}{l}\text { High } \\
\text { risk of } \\
\text { OSA }\end{array}$ & Total \\
\hline Male & $11(25.0)$ & $16(36.4)$ & $17(38.6)$ & $44(100)$ \\
\hline Female & $13(48.1)$ & $9(33.3)$ & $5(18.5)$ & $27(100)$ \\
\hline Total & $24(33.8)$ & $25(35.2)$ & $22(31.0)$ & $71(100)$ \\
\hline
\end{tabular}

Note: Figures in parenthesis indicate percentage.

Table 3: Association of obstructive sleep apnoea (OSA) with risk factors among study participants (N=71).

\begin{tabular}{|c|c|c|c|c|c|}
\hline Risk Factors & & $\begin{array}{l}\text { Low Risk of } \\
\text { OSA }(n=24)\end{array}$ & $\begin{array}{l}\text { High Risk of } \\
\operatorname{OSA}^{1}(n=47)\end{array}$ & $\chi^{2}$ Value & p-value \\
\hline \multirow[t]{2}{*}{ BMI } & $<30 \mathrm{~kg} / \mathrm{m}^{2}(\mathrm{n}=45)$ & $23(36.5)$ & $40(63.5)$ & \multirow[t]{2}{*}{1.828} & \multirow[t]{2}{*}{$0.25 \dagger$} \\
\hline & $>30 \mathrm{~kg} / \mathrm{m}^{2} \quad(\mathrm{n}=26)$ & $1(12.5)$ & $7(87.5)$ & & \\
\hline \multirow[t]{2}{*}{ Age } & $<50$ yrs $(\mathrm{n}=15)$ & $12(80.0)$ & $3(20.0)$ & \multirow[t]{2}{*}{18.138} & \multirow[t]{2}{*}{$0.00002 *$} \\
\hline & $>50 y r s(n=56)$ & $12(21.4)$ & $44(78.6)$ & & \\
\hline \multirow[t]{2}{*}{ Neck Circumference } & $<40 \mathrm{~cm}(\mathrm{n}=45)$ & $21(46.7)$ & $24(53.3)$ & \multirow[t]{2}{*}{9.087} & \multirow[t]{2}{*}{$0.0026^{*}$} \\
\hline & $>40 \mathrm{~cm}(\mathrm{n}=26)$ & $3(11.5)$ & $23(88.5)$ & & \\
\hline \multirow[t]{2}{*}{ Gender } & Male $(n=44)$ & $11(25.0)$ & $33(75.0)$ & \multirow[t]{2}{*}{4.006} & \multirow[t]{2}{*}{$0.045^{*}$} \\
\hline & Female $(n=27)$ & $13(48.1)$ & $14(51.9)$ & & \\
\hline
\end{tabular}

Note: ${ }^{1}$ High risk OSA included both intermediate risk and high risk patients; $†$ Fisher's Exact Test; *p $<0.05 \rightarrow$ significant; Figures in parenthesis indicate percentage.

Using epworth sleepiness scale (ESS) we found that $40.8 \%$ had excessive daytime sleepiness, EDS $(22.5 \%$ of participants had abnormal/severe EDS, $18.3 \%$ had moderate EDS) (Table 4). Excessive day time sleepiness was found to had statistical significant association with OSA: $16.7 \%$ with low risk of OSA had EDS as compared to $53.2 \%$ with high risk of OSA had EDS ( $\mathrm{p}=0.003)$ (Table 5).
Analysing the duration of diabetes among the study participants, we found that among 23 participants who had been diagnosed as T2DM in last two years 14 $(60.9 \%)$ had high risk of OSA. Among 23 who participants had been diagnosed as T2DM 3-5 years ago $65.2 \%$ had high risk of OSA. Among 25 participants who had been diagnosed as T2DM more than 5 years ago $72 \%$ had high risk of OSA. 
Table 4: Distribution of study participants based on their risk of excessive daytime sleepiness (EDS) assessed by using epworth sleepiness scale (ESS).

\begin{tabular}{|lllll|}
\hline Sex & $\begin{array}{l}\text { No } \\
\text { daytime } \\
\text { sleepiness }\end{array}$ & $\begin{array}{l}\text { Moderate } \\
\text { sleepiness }\end{array}$ & $\begin{array}{l}\text { Abnormal } \\
\text { sleepiness }\end{array}$ & Total \\
\hline Male & $26(59.1)$ & $10(22.7)$ & $8(18.2)$ & $44(100)$ \\
\hline Female & $16(59.3)$ & $3(11.1)$ & $8(29.6)$ & $27(100)$ \\
\hline Total & $42(59.2)$ & $13(18.3)$ & $16(22.5)$ & $71(100)$ \\
\hline
\end{tabular}

Note: Figures in parenthesis indicate percentage.

Table 5: Association of obstructive sleep apnoea (OSA) with excessive daytime sleepiness (EDS) among study participants. $(n=71)$.

\begin{tabular}{|c|c|c|c|c|}
\hline \multirow[t]{2}{*}{$\begin{array}{l}\text { Risk of } \\
\text { OSA }\end{array}$} & \multicolumn{2}{|c|}{$\begin{array}{l}\text { Excessive daytime } \\
\text { sleepiness }\end{array}$} & \multirow{2}{*}{$\begin{array}{l}\chi^{2} \\
\text { Value }\end{array}$} & \multirow[t]{2}{*}{$\begin{array}{l}\text { p- } \\
\text { value }\end{array}$} \\
\hline & $\begin{array}{l}\text { No } \\
(n=42)\end{array}$ & $\begin{array}{l}\text { Yes } \\
(n=29)^{1}\end{array}$ & & \\
\hline $\begin{array}{l}\text { Low Risk } \\
\text { of OSA } \\
(n=24)\end{array}$ & $\begin{array}{l}20 \\
(83.3)\end{array}$ & $4(16.7)$ & \multirow[t]{2}{*}{8.772} & \multirow[t]{2}{*}{$0.003^{*}$} \\
\hline $\begin{array}{l}\text { High Risk } \\
\text { of OSA } \\
(n=47)\end{array}$ & $\begin{array}{l}22 \\
(46.8)\end{array}$ & $25(53.2)$ & & \\
\hline
\end{tabular}

\section{DISCUSSION}

The results from this study highlight several outcomes that merit further attention. First, despite attending health care unit (UHC) the diabetic patients were not screened/ detected for OSA and excessive sleepiness, earlier during their routine visits to hospitals in urban slum. These findings support other research findings indicating that diabetic patients are treated inadequately or treating physicians fail to screen and initiate treatment early in course of OSA. ${ }^{14}$ Second, the study revealed that nearly two third of subjects with T2DM had high risk of OSA. Third, nearly one half of study participants had excessive day time sleepiness, which was not detected earlier or patient aware of it. This could risk the patients' lives (especially those who drive vehicles be it private or public) and others lives too, because it is well known that excessive daytime somnolence is associated with an increase in the frequency of motor vehicle accidents. ${ }^{16}$ Fourth, several risk factors were found to be associated with OSA namely, age >50years, neck circumference exceeding $40 \mathrm{~cm}$ and male sex. Multiple studies across the globe have shown similar association with aforementioned risk factors, our study confirms them in an urban slum in south India. Finally, our study revealed interesting finding that excessive daytime sleepiness was associated with presence of OSA $(p=0.003)$, which confirmed the findings from other research. ${ }^{17}$
These outcomes suggest that Type 2 diabetics need to be screened for OSA and Excessive day time sleepiness using STOPBANG questionnaire and ESS scale by the treating physician in early course of their treatment. Because of the fact that, screening for OSA was done by investigator in the study, however, testing the usage of questionnaires by primary care physician is necessary to determine how robust this screening is. Nevertheless both questionnaires are validated and each has just 8 questions, that are easy to administer and measure. ${ }^{15,16}$

Our results in addition to several recent studies of screening OSA among Type 2 diabetics indicate that assessing the risk of OSA and excessive sleepiness using these simple questionnaires may prevent several deleterious effect on diabetics. ${ }^{12,18}$

Another interesting finding of our study was there was increased risk of OSA with increased duration of diabetes among the study participants. However, this could be vice versa also but many times, OSA remains undetected among diabetics in primary clinics (UHC). The finding needs to be verified with further studies preferably prospective ones.

Present study is not without limitations. First, the study participants were not subjected to gold standard test for OSA, Polysomnography because of financial constraints and no external funding for the study. Hence, the study focussed on using validated questionnaires as a screening tool for OSA among diabetics. Second, the study did not take into account all possible co-morbidities for assessing the risk of OSA among diabetics. However major risk factors associated with OSA and DM has been taken into account in the study.

\section{CONCLUSION}

There is limited data on the burden of OSA in urban slums in India. Our study improved on previous studies by assessing the risk of OSA in type 2 diabetics in an urban slum, which has been seldom done in India. Majority of T2DM patients included in the study had high risk of OSA, which was found statistically significant association with age $>50$ years, neck circumference $>40 \mathrm{~cm}$, and male sex. The magnitude of OSA and excessive day time sleepiness we found in addition to significant association with various risk factors therefore indicates a pressing need for further research on diabetics using confirmatory tests too.

Given the complex interactions among the rising epidemics of obesity, OSA, and type 2 Diabetes in the country and involving multiple pathways, a better understanding of the relationship between OSA and type 2 Diabetes may have important public health implications in the country. There is increasing evidence that OSA is a significant risk factor for cardiovascular disease and mortality. Hence there is a pressing need for further research to screen for OSA and excess daytime sleepiness 
among all T2DM patients attending outpatient departments of primary health care units using STOPBANG and ESS questionnaires.

\section{ACKNOWLEDGEMENTS}

We thank doctors Shashi SM, Supriya P, Santhosh KB, Sushma M, Shivaleela M, Sowmya HR, Saipriya B, Sridatta GP and Ashrith SB for helping in data collection from study participants.

Funding: No funding sources

Conflict of interest: None declared

Ethical approval: The study was approved by the Institutional Ethics Committee

\section{REFERENCES}

1. Shepertycky MR, Banno K, Kryger MH. Sleep disordered breathing: differences between men and women in the clinical presentation of patients diagnosed with obstructive sleep apnoea syndrome. Sleep. 2005;28(3):309-14.

2. The National heart lung and blood institute diseases and conditions index: sleep apnea. 2009. Available at:URL:http://www.nhlbi.nih.gov/health/dci/Disease s/SleepApnea/SleepApnea_WhatIs.html.

3. Foster GD, Sanders MH, Millman R, Zammit G, Borradaile KE, Newman AB, et al. Obstructive sleep apnea among obese patients with type 2 diabetes. Diabetes Care. 2009;32(6):1017-9.

4. Punjabi NM. The Epidemiology of adult obstructive sleep apnea. Proc Am Thorac Soc. 2008;5:136-43.

5. Romero-Corral A, Caples SM, Lopez-Jimenez F, Somers VK. Interactions between obesity and obstructive sleep apnea: implications for treatment. Chest. 2010;137:711-9.

6. National sleep foundation. Sleep apnea and sleep. Available at:http:// www.sleepfoundation.org/article/sleeprelatedproble ms/obstructive-sleep-apnea-and sleep.

7. Punjabi NM. Do sleep disorders and associated treatments impact glucose metabolism? Drugs 2009;69(2):13-27.

8. Aronsohn RS, Whitmore H, Van Cauter E, Tasali E. Impact of untreated obstructive sleep apnea on glucose control in type 2 diabetes. Am J Respir Crit Care Med. 2010;181:507-13.
9. McDaid C, Duree KH, Griffin SC, Weatherly HL, Stradling JR, Davies RJ, et al. A systematic review of continuous positive airway pressure for obstructive sleep apnoea-hypopnoea syndrome. Sleep Medicine Reviews. 2009;13:427-36.

10. Tuomilehto HP, Seppa JM, Partinen MM, Peltonen M, Gylling $\mathrm{H}$, Tuomilehto JO, et al. Lifestyle intervention with weight reduction. Am J Crit Care Med. 2009;179:320-7.

11. Johansson K, Neovius M, Lagerros YT, Harlid R, Rosser S, Granath F, et al. Effect of a very lose energy diet on moderate and severe obstructive sleep apnoea in obese men: a randomized controlled trial. BMJ. 2009;399:b4609.

12. Foster GD. Obstructive sleep apnea and diabetes: what we know and what can be done? Temple University School of Medicine. Available at:https://www.mysleepquest.com/media/news/0003 2.html.

13. Brown AJ. Reuters health stories. Bruxism common with Obstructive sleep apnea, especially in men, Causcians. 2009. Available at: http://www.rtmagzine.com/reuters_article.asp?id=2 0091102clin012.html.

14. Bhatt R. Obstructive sleep apnea. Medicine Update. 2009;17(8):44-50.

15. Johns MW. A new method for measuring daytime sleepiness: the epworth sleepiness scale. Sleep. 1991;14(6):540-5.

16. McWhirter D, Bae C, Budur K. The assessment, diagnosis, and treatment of excessive sleepiness: practical considerations for the psychiatrist. Psychiatry (Edgmont). 2007;4(9):26-35.

17. Ozoh OB, Okubadejo NU, Akinkugbe AO, Ojo OO, Asoegwu CN, Amadi C. Prospective assessment of the risk of obstructive sleep apnea in patients attending a tertiary health facility in Sub-Saharan Africa. Pan Afr Med J. 2014;17:302.

18. Tasali E, Mokhlesi B, Cauter EV. Obstructive sleep apnea and type 2 diabetes interacting epidemics CHEST. 2008;133:496-506.

Cite this article as: Undi M, Annadani RR, Badesaab B. A cross-sectional study to assess burden of obstructive sleep aponea among type 2 diabetic patients attending urban health centre in an urban slum of south India. Int J Community Med Public Health 2016;3:1927-31. 